\title{
Repealing the LIFO Inventory Accounting Choice? A Review of LIFO and Inventory Management
}

\author{
Yibin Zhang1, Chunming Shi2*, Patrick Gao ${ }^{3}$, Feng Wang1 \\ ${ }^{1}$ School of Business Administration, Shanghai Lixin University of Commerce, Shanghai, China \\ ${ }^{2}$ School of Business and Economics, Wilfrid Laurier University, Waterloo, Canada \\ ${ }^{3}$ Ferrero Trading Lux S.A., Diekirch, Luxembourg \\ Email: zhangyb@lixin.edu.cn, ${ }^{*}$ cshi@wlu.ca, gaoshengxuhua@hotmail.com, wangf@lixin.edu.cn
}

Received 23 August 2014; revised 20 September 2014; accepted 6 October 2014

Academic Editor: Haiyan Li, Chongqing University of Technology, China

Copyright (c) 2014 by authors and Scientific Research Publishing Inc.

This work is licensed under the Creative Commons Attribution International License (CC BY).

http://creativecommons.org/licenses/by/4.0/

c) (i) Open Access

\begin{abstract}
Researchers in the disciplines of both Operations and Accounting have studied Inventory Management, though in relative isolation. In this paper, one of our goals is to help inform researchers in Operations Management about an extensively debated question in inventory accounting: whether to repeal the LIFO (Last-In-First-Out) inventory accounting choice? This question has received extensive scrutiny from various stakeholders including academics, businesses, and different levels of governmental agencies such as US Congress. Specifically, we provide a literature review on how LIFO affects and is affected by inventory management. This is done by first reviewing the potential determinants of LIFO inventory accounting choice and then reviewing potential interactions between LIFO and inventory management. It is our hope that this review will help stakeholders have a more comprehensive understanding of LIFO before making their decisions.
\end{abstract}

\section{Keywords}

Inventory Management, Inventory Accounting, FIFO, LIFO

\section{Introduction}

There have been two major inventory accounting systems in the world: FIFO and LIFO, standing for First-InFirst-Out and Last-In-First-Out, respectively. In Operations Management, FIFO usually means the first item entering a system (e.g., a queue) will physically exit the system first, and LIFO means the opposite. In Accounting,

${ }^{*}$ Corresponding author.

How to cite this paper: Zhang, Y.B., Shi, C.M., Gao, P. and Wang, F. (2014) Repealing the LIFO Inventory Accounting Choice? A Review of LIFO and Inventory Management. American Journal of Operations Research, 4, 351-364. 
however, FIFO and LIFO could mean something quite different: FIFO means items exiting a system will be evaluated at the purchase price of the oldest items in the system, and LIFO means items exiting a system will be evaluated at the purchase price of the newest items in the system. In other words, FIFO and LIFO in Operations Management imply something physical and in Accounting imply something financial.

Today, while FIFO (first-in-first-out) is widely adopted in almost all countries (e.g., see China Accounting Standards and International Accounting Standards), LIFO (last-in-first-out) is still used in US Generally Accepted Accounting Principles (US GAAP). Therefore, LIFO repealing debate now becomes the central topic of the Congress in the United States and academic research ([1]-[4]). Strong industry lobby groups argue for or against this inventory accounting system based on their industry interests. For the businesses involved, retailing is the most proactive industry against LIFO while oil industry strongly advocates for the retaining of LIFO. So the questions need to be answered are: should LIFO be abandoned after its use for 70 years and which potential determinants could decide the attitudes of the industry? First, some basic concepts of inventory accounting systems are to be clarified. Normally, LIFO and FIFO are the frequently used inventory valuation accounting systems. During inventory cost inflation, under LIFO, the recent higher cost is matched with the revenue, so the taxable income is reduced, thus reducing the tax and increasing the cash flow. Under FIFO, the lower cost is matched with the revenue, so the financial performance of profit increases. LIFO reserve is defined in the literature as an inventory account describing the inventory valuation difference between LIFO and FIFO. The first part of this literature review summarizes the potential determinants behind LIFO inventory accounting choice and analyzes the significance of these variables on LIFO choice in univariate and multivariate analysis. The second part mainly focuses on the interaction between LIFO choice and inventory management. Various empirical approaches and stochastic models are presented. The main purpose of this literature review is to provide a more comprehensive perspective regarding LIFO choice to the researchers from operational area. As no paper about the LIFO choice with a focus on LIFO determinants and interaction with inventory management has ever been published, this literature review is intended to fill the gap and make a contribution to this area.

The remainder of this paper is organized as follows. Section 2 introduces the determinants of LIFO choice. Section 3 includes the analysis of inventory liquidation and the inventory management strategy taken to mitigate the effect of inventory liquidation under LIFO choice. Section 4 describes the effect of LIFO reserve on just-intime manufacturing system adoption. The key challenges and future development directions are given in Section 5. Concluding remarks are presented in Section 6.

\section{The Determinants of the FIF0/LIFO Choice}

Current research is devoted to analyze the determinants behind LIFO choice. As commonly discussed, reducing tax is the most important incentive for many firms, especially large ones, to adopt LIFO inventory accounting system. Meanwhile, it was found that even though the tax saving benefit is obvious, companies remain reluctant to adopt LIFO inventory accounting choice implying that the potential non-tax reasons may force managers to balance the tax benefit with the cost incurred from shifting to the LIFO from the FIFO accounting choice.

\subsection{Tax Incentive}

It is well understood that during an inflationary period, when companies shift from FIFO to LIFO accounting, the cash flow of the firm increases due to the fact that by matching the revenue with the recent higher cost the taxable income decreases and reduces the tax. Even though there are other non-tax factors constraining firms from adopting the LIFO method, tax incentive is always a very significant variable for a firm's accounting choice. During periods of inflation, product costs and non-decreasing inventory levels, LIFO may produce the highest cost of goods sold, the lowest net income, and therefore the lowest tax payments if used for tax purposes.

[5] states that compared with other determinants, tax related cash flow will always be one of the most important factors determining the inventory accounting choices. Normally cash flow difference between LIFO and FIFO is influenced by four factors: end inventory level, inventory into price changes, marginal corporate tax rate and discount rate. Managers can only use the inventory management strategy to influence the end inventory level, so the tax incentive greatly relies on the end inventory variability.

[6] presents two models to prove that the tax saving is much larger at the year of shifting to LIFO than at other years and meanwhile, the tax saving uncertainty is strongly correlated with the managerial intention to shift. The core idea of [6] is to analyze the possible effects caused by the time shifting option and the tax saving un- 
certainty on the inventory accounting choice. Tax saving is calculated as the product of cost of goods difference between LIFO and FIFO with the marginal corporate tax rate. [6] takes six majors steps in the process to calculate the final tax savings. The first four steps divided the overall cost of the goods sold into labor cost, raw material cost and the overall overhead costs. The fifth step tries to analyze the price changing effects of labor cost and raw material cost. The final step finally combines all the mentioned cost factors into integrity of the cost of goods sold. A nonparametric Wilcoxon test was used to compare the tax savings of the switch year and nonswitching year. Three out of the four data groups are highly significant implying that current tax saving is strongly related to the LIFO/FIFO cost-of-goods-sold difference.

[7] uses the collected data from the inventory levels under their current inventory accounting method and compared the data with the possible alternative as if data which is obtained if another inventory accounting choice is used. Applying univariate analysis, [7] proves that tax saving is considerably related to inventory accounting choice. Due to the limitation of assumptions and available data, the quantitative benefits of non-tax factors can hardly be determined and the tax rate is assumed constant through the period. A more consistent conclusion cannot be made.

[8] uses time serious statistical method and comparison between different industries to test the significant variables which may have an influence on the final inventory accounting choice. The key finding is that only size and tax savings are the significant variables of inventory accounting choice. [8] further analyzes the time shifting option and demonstrated that only when the tax saving reach a certain point will LIFO inventory accounting method been chosen.

Common ground regarding the determinant of tax saving has been reached by most researchers that tax saving is one of the most significant factors involved into the inventory accounting choice. But in most cases, the tax rate is assumed to be constant and the non-tax factors were not accurately quantified due to data limitations in analysis. A consistent and stronger conclusion will be made if researchers incorporate the stochastic tax rate into models and additional data could be collected to obtain more accurate proxies of non-tax factors.

\subsection{Political Cost}

Political cost arises when the companies try to use LIFO to defer tax which is prohibited by the government which uses various methods such as anti-trust policy, nationalization as well as other regulatory methods to deter the intention of tax deferral ([9] [10]). Normally the firm's size is used as the proxy to represent the political cost in the statistical significance analysis. It was found, that the larger the firm is, the more likely LIFO would be used. In order to reduce the negative influence as the main monopoly of certain industry or excessive large profits, companies used various methods to hide the monopolistic behavior ([8] [10]). The majority of researchers show that LIFO-firms are larger than the FIFO-firms (Eller, 1989; [7]-[10]). However, [11] in their LIFO survey rejects the so called size hypothesis and allege that the second data is not reliable to be used to demonstrated the significant relationship between company size and the inventory accounting choice.

\subsection{Agency Cost}

Executives don't always align their interests along with that of the shareholders. They act either to increase the total value of the company or try to increase their personal interests at the sacrifice of the interests of the shareholders ([12]). It is generally accepted by previous studies that the interest conflict between managers and shareholders is caused by two main reasons: 1) the managers are worried about the underperformance of the company which could lead the take-over risk by its competitors; and 2) the compensation plan of the managers is proportionate to the financial performance of the company ([13]). The two main streams, which have been moderately analyzed, are ownership structure and compensation plans. Both of them can affect the relationship between managers and shareholders and are part of the possible solutions to the problems. [8] states that the misaligned incentives among the shareholders would damage the relationship between shareholders and managers, and between shareholders and bondholders. The ownership structure, compensation plan, and capital structure of the firm are the three main proxies of the agency costs.

\subsubsection{Ownership Structure}

As stated by [12] and [13], an association between ownership structure and inventory accounting choice is based on two premises: 1) the mangers and shareholders possibly conflict with each other over the inventory accounting choice; and 2) the ownership of the firm can partly solve the problem of the conflict. 
[13] divides the ownership structure into two main groups: managerial ownership and outside ownership; meanwhile, he considers a lot of other factors in his empirical model. He set up a regression model to test the significance of the independent variables of managerial ownership (MGR), outside ownership (OUTCON), leverage (LEV), inventory variability (INVVAR), and size (ASSETS), and indicator variables of wood products industry, food industry, electronics industry, and publishing industry.

$$
\begin{aligned}
\operatorname{Prob}(\mathrm{LIFO})= & a+b_{1} \mathrm{MGR}+b_{2} \mathrm{MGR}^{2}+b_{3} \mathrm{OUTCON}+b_{4}(\mathrm{OUTCON} \cdot \mathrm{MGR})+b_{5} \mathrm{ASSETS}+b_{6} \mathrm{LEV} \\
& +b_{7} \mathrm{INVVAR}+b_{8} \mathrm{WOOD}+b_{9} \text { ELECT }+b_{10} \mathrm{FOOD}+b_{11} \mathrm{PUB} .
\end{aligned}
$$

[13] finds that managerial ownership and outside ownership do interact with each other to influence the inventory accounting choice, so an interaction variable (OUTCON·MGR) is also added. The univariate analysis rejects the outside ownership hypothesis that LIFO choice is positively related to the increase of outside ownership and shows that LIFO choice is more preferred when the managerial ownership is high or low than when it is in between. To further test the results, a multivariate analysis is used. The results of that analysis agree with the univariate analysis that LIFO is preferred when managerial ownership is low and high. Compared with other regression models, Niehaus's model takes a more comprehensive perspective by incorporating almost all the potential determinants with a focus on the factor of ownership structure.

[14] takes a similar viewpoint but divide the companies into private and public owned. It is widely stated that public companies are less inclined to use the LIFO method to improve their financial performance while private companies prefer LIFO to increase their cash flows because of the lower tax paid. [14] uses the matched-pair test with controls of size and industry type to test the significant of ownership structure. The private companies are used as the benchmark to evaluate the accounting choice behavior of public firms.

[15] presents the discriminative multivariate model to analyze the independent variables of size, ownership variable and capital structure. The empirical results show that size is the most significant variable of the LIFO choice. Ownership structure is also a significant factor at the level of 0.05 in the multivariate analysis compared with the significance level of 0.10 at the univariate analysis when size is controlled. It implies that size interacts with ownership structure to affect the LIFO choice.

However, the most significant drawback of current research is the assumption that the company is owner-controlled if the largest shareholder has $20 \%$ or more of the total shares and the company is manager-controlled if no shareholder owns $5 \%$ or more of the total shares. Neither the justification for creating such an artificial dichotomy from a sample of continuous data on the concentration of stock ownership, nor the statistical implication of this practice, is evident ([15]). [15] proposes that in order to avoid the arbitrary classification of firm ownership, a continuous variable measuring the degree to which a firm is closely held should be employed.

\subsubsection{Compensation Plans}

As the compensation plans for managers are dependent on the financial performance of the firm, the managers are less inclined to adopt LIFO which can lead to a lower financial performance ([16]). Current research has found a positive relationship between managers' compensation plans and firms' financial performance. [13] states that if the company does not adjust the inventory accounting method, it is likely that a positive correlation between managerial compensation and company income. Consequently, managers may have less incentive to choose the income decreasing inventory method of LIFO. A conflict may arise between the managers and shareholders because managers will prefer not to use LIFO so as to increase their compensation while shareholders will intend to adopt LIFO to reduce the tax paid so as to increase the cash flow for the company.

However, contradicting to the theoretical allegation, it was proven that, in average, changes to LIFO do not have significant negative effects on executives' compensation, no matter of whether kind of forms of compensation was provided ([17]). [17] presents a regression model:

$$
\mathrm{LnP}_{i}=a_{0}+a_{1} \mathrm{LnINC}_{i}+a_{2} \mathrm{OM}_{i}+a_{3} \mathrm{EC}_{i}+a_{4} \mathrm{OM}_{i} \cdot \mathrm{LnINC}_{i}+a_{5} \mathrm{EC} \cdot \mathrm{LnINC}_{i}+a_{6} \mathrm{OM}_{i} \cdot \mathrm{EC}_{i} \cdot \mathrm{LnINC}_{i}+e_{i}
$$

where the dependent variable is the dollar amount of the executive's compensation and the independent variables are the annual profit reported by the companies $\mathrm{INC}_{i}$ and two dummy variables $\mathrm{OM}_{i}$ and $\mathrm{EC}_{i}$ indicating whether the company is owner-controlled or manager-controlled and whether the company shifted to LIFO or not. The empirical results are shown in three aspects:

1) Before changing to LIFO choice, the companies which shift to LIFO compared with the companies still retain at FIFO enjoy a higher bonus plan. 
2) At the changing year, companies successfully align the benefits of the managers with the shareholders to significantly increase the proportion of the bonus plan in the overall compensation plan.

3) After the changing to LIFO, the interaction term EC (Executive Compensation) $\times \ln I N C$ (income) is significant which demonstrate that the companies which shift to LIFO are quite more flexible in reconfiguration of the compensation compared with the companies which are still stick to the FIFO choice.

[18] takes a similar view that the compensation plan includes various incentive plans so the managers need to balance various compensation plans to see what the ultimate effect on their overall compensation amount. [18] uses three independent variables: income-based bonus plan, ownership structure, and leverage to test their significance on independent LIFO choice. The final empirical results show that the bonus plan is not correlated with the LIFO choice, the same with previous studies. One reason is that when the shares become a part of the compensation plan, managers are usually caught in a dilemma, such as stated by [13], that LIFO results in a higher stock price and therefore greater value for the managers' shares, meanwhile LIFO decreases the reported income and income-based bonus compensation. The mere existence of the compensation plan cannot determine the preferred accounting choice anymore, as the compensation plan structure now becomes quite comprehensive, incorporating different incentive plans for the managers. Meanwhile, the compensation plan becomes very flexible to adapt for the interest conflict between managers and shareholders.

\subsubsection{Capital Structure}

[19] finds that the capital structure affects the inventory accounting choice as well. Since then, [8] [15] [18] have stated that companies which heavily rely on external financing try to avoid the income decreasing inventory accounting method which will lead to a more restrictive covenants on contracts levied by financial institutions. Different papers try to analyze the relationship between the components of the capital structure and the inventory accounting choice to provide more practical insights for the capital and inventory accounting policy. [19] selects two groups of companies according to two different costing methods-full costing method and successful efforts to test the significance of long-term debt. [19] concludes that firms using a relatively large amount of long-term debt tend to oppose LIFO which reduces the financial performance level. [8] also uses the proxy of net tangible assets/long-term debt to test the significance of its positive relationship with LIFO adoption. Meanwhile, other proxies are also proposed for the debt covenant constraint. [8] and [18] test the hypothesis that LIFO adopters have a larger pool of retained earnings available for dividend payments relative to recent dividend payments, than non-adopters. [18] also states that the level of working capital and credit policy are required by most covenant contracts.

\subsection{Investments and Production Character}

There are two streams for the determinants of the accounting choice. One is focused on the deterministic factors such as the firm size, capital structure, and covenant constraints, etc. The other one is concentrated on a more realistic, dynamic and interactive accounting, investment and operational policy choice.

[8] states that difference in production and purchasing opportunity provides firms with different comparative advantages in adopting LIFO or FIFO. One of the key issues involved is how to use the production and purchasing policy to keep the end inventory level constant. Because each year, as the inventory purchased or produced, the new inventory will be added to the base inventory. It looks like a new layer of the inventory is added on the top. Therefore, the researchers treat the total inventory as integrity with many layers. During a new year, if the inventory consumption is larger than the inventory purchased or produced at that year, the base inventory from previous years will be used or called liquidated. In common, the inventory cost is increasing. The lower inventory cost of the liquidated inventory matches with the revenue so the taxable income increases resulting into a higher tax and lower cash flow which is against the original tax purpose of LIFO adoption. As the end-inventory level significantly influences the tax, operation policy, accounting choice and tax should be viewed in a dynamic and integrated manner. Specifically, companies should use production and purchasing policies to keep the end inventory at the optimal and stabilized level, meanwhile still trying to minimize the tax.

As introduced by [9], the Ricardian Hypothesis states that as firms are endowed with different production-investment opportunity sets, then the managers' inventory accounting choice can be predicted by the comparative advantage in tax cost minimization associated with the production-investment opportunity set of each firm. IFRS (International Financial Reporting Standards) allows only cost method to be used to calculate the in- 
ventory valuation while mark-down is prohibited. Such regulation implies that companies with large inventory price fluctuations may have advantage in adopting FIFO while companies with steady inventory price may prefer to use LIFO. Meanwhile, the achievement of tax minimization under LIFO requires a stable end inventory level. [9] supposes that comparative advantage in adopting LIFO is greatly dependent on the next three variables: stochastic inventory price, stochastic inventory variability, and bookkeeping and tax reporting cost. [9] uses eight proxy variables to reflect the characteristics of the production-investment opportunity set that are relevant to the choice of inventory accounting method. The eight variables are price variability, inventory variability, accounting income variability, absolute firm size, relative firm size, capital intensity, inventory intensity and industry classification. The univariate analysis shows that the size variable is a very significant factor for the LIFO choice, but the size is also significantly related with other determinants such as capital intensity which are also significantly related to LIFO choice. Hence, the conclusion about the significance of size would be spurious. However, the analysis shows that inventory variability is independently significant for LIFO choice implying the significance to keep end inventory level constant. According to multivariate analysis, the industry classification variable is significant what could be explained by the fact that different industry has different inventory price movements and companies in different industry possess different production and investment opportunity set. Basically, the multivariate analysis rejects the political cost and agency cost assumptions, but supports the Ricardian hypothesis because the significant variables left are inventory variability, industry classification, and inventory price variability.

[7] also indicates that the inventory accounting choice is based on the assumption that company makes its strategic inventory accounting choice according to the characteristics of its financing, operation and accounting systems. [7] presents three variables which are related to the LIFO choice. Total sales or holding gains are used to measure the size of the company. Fixed asset/total asset ratio is used to reflect the capital intensiveness. Covariance of inventory variation describes end inventory fluctuation. The results prove that companies which adopt LIFO tend to be larger, with more stable end inventory and stronger capital intensiveness.

To summarize the determinants of LIFO inventory accounting choice, the major potential variables which have been extensively studied are listed. Univariate and multivariate analysis is used to test their significance on the LIFO choice. Due to the limit of the current research, common ground has not been reached for all of the analyzed variables and some variables only occur in the analysis of one specific paper, so we don't put all the possible variables but those which are usually used and largely agreed upon in the current research. Authors and measurement are also included into the table for the convenience of reference and comparison with further research.

\section{Inventory Liquidation}

The extensively studied area of the interplay between inventory management and LIFO inventory accounting choice is inventory liquidation. As mentioned, the total inventory is treated as integrity with many inventory layers which are the inventory accumulated in the previous years. If the inventory consumption is higher than procurement or production of the new inventory in the new period, the older layer of inventory will be consumed. Such consumption of the previous base inventory is called inventory layer liquidation. Unlike the general understanding of inventory liquidation where inventory are sold at a cheaper price than original price in order to increase the sales volume, the inventory liquidation concept of LIFO analysis here is more focused on the inventory liquidation quantity which is the depletion of the base inventory quantity of the previous years. Papers analyzing inventory liquidation mainly focus on four aspects: the measurement and determinants of inventory liquidation, the consequences of inventory liquidation, the dynamic ordering models to mitigate inventory liquidation, and inventory pooling strategy to interact with inventory liquidation. Papers considering the last two aspects aim to reduce the negative effect of inventory liquidation on LIFO tax minimization purpose by using inventory management strategy consisting of dynamic order policy with purchasing and production strategy, and inventory pooling policy.

\subsection{Inventory Liquidation Determinants}

As the end inventory level can significantly influence the tax benefit under the LIFO inventory accounting method, it should be treated as a part of the function to maximize the cash flow. When inventory liquidation occurs, 
current sales revenue matches with the previous lower inventory cost during the inflation period, so taxable income increases respectively. This leads to the decreased current cash flow due to the increased tax. Companies try to avoid the inventory liquidation by means of intra-year purchasing or production in order to keep the end inventory level stable for the tax concern while some companies otherwise liquidate their end inventory for other reasons.

The literature regarding the determinants of the inventory liquidation could be classified into three main groups. Generally speaking, the managers need to consider and balance three relationships before making the inventory liquidation decision: holding cost vs. liquidation cost, cost of capital vs. liquidation cost, and economic changes vs. liquidation lost. Dynamically, the managers need to combine the accounting policy and operation policy simultaneously in terms of integrating inventory management, capital investment management and earnings management.

\subsubsection{Holding Cost}

The most significant consequence of holding an excessive end inventory to avoid inventory liquidation is the increase of inventory holding cost. [20] states that the trade-offs involved in the purchasing decision to replace the liquidated inventory is reduced federal income tax against higher carrying costs and order or setup costs. Generally, there are eight components of inventory carrying cost:

1) the cost of capital for purchased inventory,

2) additional property taxes,

3) warehousing costs,

4) insurance cost,

5) transportation cost,

6) handling cost,

7) deterioration cost,

8) obsolete cost.

Since some of the holding costs are tax deductible, such as cost of capital and property taxes, the decision rule is based on a comparison between the present value of these costs and the present value of the cost of the LIFO layer liquidation.

\subsubsection{Capital Cost of Investment}

Before managers make the investment choice, the risks of investment, interest rates and rate of return are the important factors to be considered. The main risk of inventory investment is inventory obsolescence. High interest rates will result in high inventory carrying costs. These high rates also present alternative economic opportunities for funds invested in inventories if there is a belief that the inflation rate will decrease in relation to the interest rate ([21]). [22] uses the questionnaire to test the significance of key factors determining inventory accounting choice. Among the executives, most of them identify cost of capital as one of the most critical important factors.

\subsubsection{Economic Condition Changes}

The overall economic condition significantly influences the inventory liquidation choice. The economy in recession leads to a dip of the demand causing the company to reduce its inventory in order to save cost ([21] [23]). [23] identifies the variables of sales' volumes and earnings to reflect the firm size and economic performance in the inventory liquidation choice. [21] states that the decreasing demands caused by the sluggish economy as a whole pushes the company to reduce the cost or to improve the reported income. Inventory liquidation can greatly help to alleviate the cash flow strain and relax the debt covenant constraint especially in the economic recession.

Besides the three main considerations, industry specificity also draws much attention in the literature because certain industries are more sensible to the business cycle phenomenon than others. [22] indicates that LIFO companies in cyclical industries should take a special care to manage their LIFO inventory levels better. Meanwhile, the characteristics of the industrial products also determine the inventory accounting choice. The retail industry is much more likely to take the FIFO method because the fast inventory turnover significantly constraints the possibility of tax manipulation and FIFO can better reflect the operational performance of the retailers. While the oil\& gas industry prefer the LIFO industry ,due to the long time storage of its inventory and the 
fluctuations of the oil price in the international market, both of which provide the possibility of tax manipulation.

\subsection{Inventory Liquidation Consequences}

The extant literature provides contradictory perspectives regarding the incentives behind the inventory liquidation and its consequences. On the one side, [8] implies that companies are foregoing the tax benefits of switching to LIFO due to the potential cost caused by possible future LIFO layer liquidations. [24] finds that cash planning difficulty mostly follows the possible inventory liquidation after LIFO is adopted. [25] holds the same view that the sudden increase of tax liability can quickly diminish the tax deferral benefits from previous period and cause severe budget planning and allocation problems. On the other side, [26] argues that inventory liquidation is beneficial to the stabilized reported income and help to alleviate the restrictive debt contract covenants.

\subsection{Dynamic Order Policy}

The conventional dynamic order policy problem has already been extensively analyzed in the past. The cost factors normally involved are order cost, carrying cost, obsolete cost, stock-out cost along with other considerations such as customer satisfaction level. However, few studies have ever incorporated inflation and tax, the two most important economic factors, into the models. When inventory cost changes, the optimal order size will also be influenced due to tax concerns. Optimal order size, in turn, will be dependent on the cash flow changes. Firms need to consider the cash flow choice and the order size decision simultaneously. The existing literature treats the end inventory level as an exogenous variable where management has no control. However, since the LIFO firms' tax liability is partly a function of year-end inventory level, management can control the year-end inventory levels based on the LIFO or FIFO choice.

[5] proposes the anticipation hypothesis and incentive hypothesis, showing that the accounting choice and operation choice are mutually influenced by each other. The accounting choice should consider the future anticipated operational condition such as inventory levels which could be changed due to purchasing and production policy while the operation policy, such as the purchasing or manufacturing policy, could be altered and adjusted for the end inventory level to cater to the chosen accounting choice in order to maximize the tax benefit. [5] establishes the one-period optimal inventory policy model considering the LIFO and FIFO tax incentives. The cost, decisions and outcomes are treated and updated on an annual basis. The variables involved in the model are the order-up-to quantity and demand, which are notified only at the end of the year. The model is used to test the following testable implications:

- during inventory price inflation, LIFO end inventory level will be higher than that of FIFO;

- during inventory price deflation, LIFO end inventory level will be lower than that of FIFO;

- the existence of additional layer of LIFO inventory price changes will increase the optimal inventory level for sale under LIFO and FIFO.

For the previous models such as the one established by [5], the end inventory is considered as an exogenous variable and managers can't have an influence on it. However, under LIFO, tax liability is a function of the end inventory. Managers try to keep a constant end inventory to avoid liquidation, though the increased inventory level leads to a higher holding cost. Meanwhile, the purchasing and production cost should also be considered. Based on these considerations, the models set up by [27] and [28] attempt to treat the purchasing and production under control and do not consider the end inventory as an exogenous variable.

[27] sets up the model of expected after tax profit, under LIFO and FIFO in both single-period and multi-period:

$$
\begin{aligned}
\Pi(z)= & p E[\min (z, D)]-c_{1}(z-x)-h E\left[(z-D)^{+}\right]-s E\left[(D-z)^{+}\right] \\
& -M\left\{\left(p-c_{0}\right) E[\min (x, D)]+\left(p-c_{1}\right) E\left[\min \left(z-x,(D-x)^{+}\right)\right]\right\}+\alpha c_{2} E\left[(z-D)^{+}\right] .
\end{aligned}
$$

where $p E[\min (z, D)]$ is a stochastic revenue term, and $D$ is the random demand. The cost of goods purchased is $c_{1}(z-x)$. Annual holding and shortage cost are defined by $h E\left[(z-D)^{+}\right]$and $s E\left[(D-z)^{+}\right]$respectively. The salvage value of goods remaining at the end of the year is $\alpha c_{2} E\left[(z-D)^{+}\right]$, where $\alpha \in[0,1]$ 
is the discount factor. The results present the relationship between tax, inventory order policy and valuation convention. For the single period model, demand is treated as a non-fixed variable and will only be known at the end of the period. Annual order is aggregated into a single quantity which is the total volume of the expected demand of the next periods. Optimal inventory order policy under FIFO inventory accounting choice is a deviation of the typical Newsboy problem. While the optimal inventory order model under LIFO is diminished to be a first-order equation. The single period models of FIFO and LIFO also consider the relationship between relative optimal inventory level under LIFO/FIFO and various responses to the changes in tax rate, inventory costs and inventory level. The single period models of LIFO and FIFO are extended into multiple period problems. For FIFO problem, [27] add an additional assumption that inventory turnover fluctuates across the periods; the optimal solution is achieved as a closed form myopic policy. For LIFO, the expression is a function of the optimal inventory level of each inventory layer. Given the sequence of inventory levels and ordering policy, the after tax profit under LIFO could be found in the multi-period model. Finally, [27] set a two-period setting, where dynamic order policy is implemented under LIFO and FIFO, and then the optimal inventory level under LIFO and FIFO is compared. A search algorithm is used to get the best solution for LIFO, while a variation of the best solution from the FIFO multi-period model is achieved for FIFO model in this case.

[28] takes a very special perspective in looking at the end inventory problem. The purpose of his paper is to analyze the effects caused by the dynamic ordering policy which is taken to keep the end inventory constant from a social welfare standpoint. [28] introduces the concept of dollar value of LIFO inventory liquidation. The measuring of the inventory in dollars provides conveniences to put different kinds of products into the same inventory pool even though they are not economically or physically correlated. Under LIFO inventory liquidation, the main purpose of companies is to maintain the dollar value of the inventory at the end of the new period to be not less than the beginning value. Even though physical products get liquidated or new products are purchased during the new period, as long as the end inventory into dollars is equal or larger than the beginning inventory values, the inventory is not financially liquidated. [28] strives to establish a model, in order to see the LIFO end inventory controlling effect on resource allocation. A maximum taxable income model has been set up to calculate the taxable income even though it is slightly different from the economic income. An after-tax economic model is also built to measure the total social welfare. The final production effects and Pareto-Optimality shows that the measures used to keep the end inventory stable for LIFO companies introduce ineffectiveness into economic resources allocation within the society.

[29] extends the models established by [27] by considering both the intra-year and end-year purchasing and production decisions in a nonstationary price and demand environment. [29] maximizes the following function in a $T$-year period:

$$
\sum_{t=1}^{T} \alpha^{t}\left\{\sum_{i=1}^{p}\left[\left(1-\tau_{t}\right)\left(s_{i}^{t} D_{i}^{t}-h_{i}^{t} I_{i}^{t}\right)-p_{i}^{t} y_{i}^{t}\right]+\tau_{t}\left(\sum_{j=1}^{N} p_{j}^{0} Z_{j}^{t}+\sum_{j=N+1}^{N+1} \sum_{i=1}^{P} p_{i}^{j-N} Z_{j, i}^{t}\right)\right\} .
$$

Within each year there are $i$ time periods, when the managers have to make a purchasing or production decision. The objective of the model is to maximize the after-tax profit of the company. The cost structure includes unit purchase (production) cost $p_{i}^{t}$, unit holding cost $h_{i}^{t}$, tax rate $\tau_{t}$ and sales prices $s_{i}^{t}$. The model involves some assumptions to facilitate the trade-off between tax and the cost incurred to carry excessive end inventory. Demand $D_{i}^{t}$ is assumed to be known with certainty or, alternatively, demand could be forecasted with $100 \%$ accuracy. Stock-out cost is totally eliminated from the model implying that the demand variance is captured by the safety stock. Meanwhile, production capability, distribution channel, etc. are excluded from the model for simplicity. The mathematic model is solved by a non-linear formulation which reduced to be a linear formulation due to the assumption of cost inflation.

[30] holds the same view by using a mathematical model to prove the mutual relationship between the purchasing policy and inventory accounting choice where the purchasing policy will have a huge influence on the final inventory level meanwhile the end inventory level determines the further purchasing quantity. [30] establishes a three-period model with two demand scenario: low demand and high demand. In order to maximize the manager's compensation as well as the cash flow of the company, the managers have to decide the purchasing quantity based on the forecast of demand of the next period. The key issue here is to choose the optimal inventory level which not only maximize the utility of the manager's compensation but also minimize the divergence of interested between the managers and shareholders. Two contract settings are given: contract based on income 
and contract based on income and inventory liquidation loss. Two inventory accounting scenarios are further presented: inventory accounting choice without tax effect and inventory accounting choice with tax effect. The results of the mathematical modeling show that given managers' incentive, LIFO tax incentive distorts efficient purchasing and production policy. As [30] generally agrees with most of the established arguments in the literature, the noteworthy thing is acquisition cost on the inventory accounting choice. As the model can't reflect this factor, further research has to focus on the effect of purchasing price changes on LIFO choice. Meanwhile, [30] suggests the mix inventory strategy, where some of the inventory adopts LIFO and rest for FIFO. An optimal inventory strategy for FIFO or LIFO alone should be further extended under inventory accounting incentives.

In order to better fit the stochastic demand settings, [31] introduces an alternative method which incorporated a second variable:

$$
\alpha^{n-1}\left\{s_{n} z_{n}-c_{n}\left(Y_{n}-x_{n}\right)-\bar{c}_{n}\left(z_{n}-Y_{n}+I_{n}\right)^{+}-h_{n} \max \left(\left(Y_{n}-z_{n}\right), I_{n}\right)-\tau\left[s_{n} z_{n}-h_{n} \max \left(\left(Y_{n}-z_{n}\right), I_{n}\right)-\mathrm{COGS}_{n}\right]\right\}
$$

where the procurement cost at year $n$ is $c_{n}\left(Y_{n}-x_{n}\right)-\bar{c}_{n}\left(z_{n}-Y_{n}+I_{n}\right)^{+}$, which is comprised of the cost of first order and second order, when $z_{n}>Y_{n}-I_{n}$; holding $\operatorname{costs}_{n}=h_{n} \max \left(\left(Y_{n}-z_{n}\right), I_{n}\right)$, and

Taxes $_{n}=\tau\left[s_{n} z_{n}-h_{n} \max \left(\left(Y_{n}-z_{n}\right), I_{n}\right)-\mathrm{COGS}_{n}\right]$. The second order guarantees that the inventory level not only satisfied the excessive inventory which is over the previous up-to-level inventory but also help to maintain the desired minimum end inventory level. In this case the fixed order cost is ignored for simplicity. However, in reality the accumulation of the fixed order cost incurred by multiple second orders across multiple years may outweigh the tax saving from the avoidance of inventory liquidation. In future research, a dynamic variable of the second order cost should be incorporated.

Considered the tax concern of LIFO, the purchasing and operation decisions are intended to keep the end inventory floated to avoid inventory layer liquidation. Such decisions are not always wise to minimize the total cost as far as the holding cost is high if more buffer inventory has to be carried. The intra-year and end-year production and purchasing decisions should be made into a more dynamic way by combing the tax liability, possible holding cost, production and purchasing cost as well as potential inventory cost changes. Under so many assumptions for the current models, further research regarding the end inventory level control could be extended to different areas, considering the tax liability of LIFO. The extended models could reflect a longer planning period, production capacity, stock-out cost and stochastic demand changes. The models should include the factor of fixed order cost which is a major factor for the function of after-tax profit maximization if companies are free to make several additional orders due to demand changes. An integer programming model could be expected if fix cost and decreasing inventory price are included. In order to better catch the interplay between intra-year and end-year operation decision, a more comprehensive stochastic model is going to be established.

\subsection{Inventory Pooling Strategy}

\subsubsection{Inventory Pooling Measurement and Determinants}

In Operation Management area, the concept of inventory pooling stands for the risk pooling strategy in order to diminish the risks and losses caused by the variation of customer demand. The main forms taken are centralized warehousing, common components, delayed differentiation, product substitution and e-tailing. While in LIFO inventory analysis, the main function of inventory pooling is intended to pool the inventory so as to reduce the loss of tax benefit caused by inventory liquidation. As mentioned before, inventory liquidation will match the recent revenue with the previous cost, so the profit will increase so as to increase the tax levied. The most important prerequisite of the inventory pooling strategy in LIFO is the introduction of inventory pooling into dollar values. Different from inventory pooling in units, dollar value provides the possibility to group the products which are counted based on different measurement, such as tons, kilos, etc. Normally, the inventory pooling of units is based on the classification of characteristics of the products, while the subdivision of inventory pooling of dollar values has resulted at least in part from the habits or customs of business management, government policy and, in some cases, mechanical convenience in inventory computation ([32]). The dollar value of inventory into multiple-item pools under LIFO allows for the reduction of inventory of some products to be offset by the increase of inventory of other products. The similarity of purpose between the inventory pooling strategy under general Operation Management and the inventory pooling strategy under LIFO inventory management is 
that both strategies are intended to diminish the risk of variation of customer demand by aggregating the inventory levels. The justification of the expansion of pooling should be either that the extended pooling can better allocate the cost under LIFO or the pooling better serves the objective of LIFO to match the cost with revenue.

\subsubsection{Single Pool}

The IFRS has set different pooling regulations for the manufacturing/processing and retailer/wholesale industries. Manufacturing/processing is allowed to have one pooling, while retailer/wholesale is required to adopt the pooling subdivisions to reflect the diversification of the product portfolio ([33]). This regulation sets the maximum limit for the degree of freedom of managerial discretion, while the managers still have a moderate freedom to pool the inventory for tax incentives. A widely accepted wisdom within the industry holds a view that if managers follow a strategy of deferring income taxes by the use of LIFO, the objective should be to minimize the number of LIFO pools subject to these regulatory constraints. The justification and rationale behind this is following: the more items a company combines in a single pool, the more likely it is that a decrease in some items will be offset by an increase in others. Moreover, the use of fewer pools tends to reduce the administrative burden of applying LIFO ([34]).

\subsubsection{Multiple Pools}

[35] directly attacks the general wisdom, that single pooling is a good solution for inventory liquidation. Even though single pooling is not always inaccurate, but it violates the inventory pooling decision process. As suggested by [35], there are four questions to answer in order to make a right inventory pooling decision:

1) How the purchasing decision is going to be influenced by the future inventory cost changes?

2) How the prices of different products move together?

3) How to stock different products?

4) How the inventory will be liquidated in the future?

The key determinant of the pooling decision is how the inventory prices' changes are interacted with inventory quantity changes. [35] compares the advantages of a single pool with multiple pools based on four observations where the inventory price change interacts with the inventory quantity changes. Single pooling is always preferred when the inventory has both highest price changes and highest quantity changes; multiple pooling is always preferred when the inventory has both lowest price changes and highest quantity changes. If inventory price and quantity level remain stable across time, there is no difference between single pooling and multiple pooling. After years of price instability the inventory price starts to stabilize while inventory quantity still keeps growing, the cost-of-goods difference between single pooling and multiple pooling will keep growing as well. The main purpose of these four observations is to provide a portfolio of scenarios to the managers and facilitate in making the right pooling decision under various situations of inventory price and quantity changes. Note, that no fixed pooling strategy is right all the time. The pooling strategy should be constantly updated considering the inventory changes.

However, [35] considers only four possible scenarios. Meanwhile there are many other possibilities of the interaction between inventory price and quantity changes. For example, the inventory price keeps decreasing before entering stability, then price suddenly drops. Under this condition, which inventory pooling strategy is preferred? At the same time, for those four observations, it is assumed that inventory quantity of each product keeps increasing. It means, inventory liquidation is not allowed. However, inventory liquidation is possible for many products in reality. Thus, further research could be extended by relaxing this assumption to see how inventory liquidation could be involved into the inventory pooling strategy.

\section{Just-in-Time and Inventory Accounting Choice}

Though there is no specified concept of a just-in-time manufacturing system, the most important characteristic of this new system aims to reduce unnecessary waste and improve operational productivity. One of the most significant achievements of the system is to significantly reduce the WIP (work-in-process) inventory. Inventory accounting choice and end inventory transaction policy are usually combined in order to manage earnings. The significant reduction of the inventory constrains the ability of using earnings management tool to manipulate the profit for the company. [36] finds that the LIFO reserve level is correlated with the intention of the company to a adopt just-in-time system. They suggest that companies which have limited LIFO reserve are highly involved in earnings management, have less intent to adopt the just-in-time system. 
Normally, the inherent tax incentive behind the LIFO encourages the build-up of the inventory, which increases the cost of holding, maintenance, and obsolescence as well as other inventory related costs. [37] examines the end of the period purchasing as a function of the inventory accounting choice and find that the purchasing decision could be driven by the tax incentive. The tax incentive ultimately leads to inefficient inventory management. According to the just-in-time theory, purchasing will only be activated when necessary. This is the most significant cost saving method in inventory management. The inventory management inefficiency caused by the tax incentive totally counters the just-in-time principle. Further research could quantify the difference between the tax savings of the LIFO method without adopting the just-in-time savings and the inventory management inefficiency that could have been avoided.

\section{Future Development}

Current research is primarily dedicated to find and analyze the potential determinants of LIFO inventory accounting choice. Till now, the variables representing firm's physical characteristics, operational features, investment, tax policy, etc. have been proposed and analyzed in the univariate and multivariate analysis. Several factors are considered to have significant effect on LIFO choice even though further research is still anticipated for the rest of factors which have not been extensively studied. The univariate and multivariate analysis of the potential determinants is quite helpful because it provides a key list for the companies to consider before an inventory accounting choice is made. Even though multivariate analysis reached some conclusions regarding the collinearity among potential determinants, the interaction effect among factors still needs further attention from the researchers. The incentive behind is that the significance test of the individual determinant benefits the companies before they choose the inventory accounting system based on specified characteristics. The key task for the companies during the using of LIFO system is to make a trade-off between the tax benefit loss and the cost incurred to change their organizational features. Further analysis of the interaction between the potential determinants provides a clear picture of the necessary adjustments to compound the key characteristics at the lowest opportunity cost. Thus, further research on the potential determinants of LIFO choice should be directed into establishing the procedures managing the primary determinants to minimize the tax in the process of using the LIFO system.

Tax and inflation factors have been included into the dynamic order models to reflect the tax liability of LIFO inventory accounting system under inflation. To maximize the after-tax profit, the end inventory should be stable and not less than the beginning inventory level. Various stochastic models were established by including intra-year and end year purchasing and production decisions to consider a trade-off between inventory holding cost, tax cost, purchasing and operation cost, etc. and to minimize the total cost of the company under LIFO. Although some of the models treat inventory price and demand as stochastic variables, none of them intended to provide any method to mitigate the demand and price variance under LIFO. Further research is required in this area in order to lower the demand variance risks and increase customer satisfaction. The possible approach is to find the optimal safety stock level in the dynamic order models to catch the demand variance under LIFO. Meanwhile, models could be used to analyze the interaction between inventory pooling strategy and dynamic order strategy in order to diminish the associated risk.

Inventory pooling decision is one of the strategies to mitigate inventory liquidation risk. Current research discusses the choice of single or multiple inventory pools strategy. However no papers have ever been published regarding the optimal number of inventory pools in order to reduce inventory liquidation. Further research can focus on establishing the models of the interplay between inventory price changes and inventory quantity changes to get the optimal inventory pool number and minimize the total cost considering inventory liquidation minimization requirement.

\section{Summary}

This study is partially motivated by the current debate in the US Congress regarding the repeal of the LIFO inventory accounting choice. Hence, a detailed literature review of LIFO inventory accounting choice is necessary to provide a more comprehensive view to various stakeholders. Furthermore, this review aims to inform researchers in Operations Management, many of whom are unware of this debate. To this end, this paper classifies the previous research into two areas: the determinants of LIFO inventory accounting choice; the interplay between LIFO inventory accounting choice and inventory management. The effect of LIFO reserve on the just-in- 
time manufacturing system adoption is also presented. Further research is suggested to provide a more generalized picture to the operation managers regarding the possible determinants behind their inventory accounting choice in order to better fit the company in terms of its investment, operation, and other physical characteristics. The interplay between LIFO inventory accounting choice and inventory management research should be further extended by considering more potential inventory related factors.

Last but not least, although inventory management is a fundamental issue in both Operations Management and Accounting, research on the interface between these two disciplines has been limited. The recent establishment of the Department of POM-Accounting Interface at Production and Operations Management Journal indicates that there has been an increasing interest in this research direction. It is our hope that this research can encourage more research on the Interface of Operations and Accounting.

\section{References}

[1] Carpenter, B.W. and Boyle, D. (2012) The Impending Demise of LIFO: History, Threats, Implications, and Potential Remedies. Journal of Applied Business Research, 28, 645-650.

[2] Harris, P. and Dilling, P. (2012) Managerial Opportunities Post the Last in First Out Methods. The Journal of Global Business Management, 8, 160-165.

[3] Harris, P. and Yun, J.K. (2012) The Positive Future Outlook of the Last-In-First-Out Inventory Method. The 2012 Orlando International Academic Conference, 2-4 January 2012, Orlando.

[4] Jesswein, K.R. and Houston, S. (2010) The Changing LIFO-FIFO Dilemma and Its Importance to the Analysis of Financial Statement. Academy of Accounting and Financial Studies Journal, 14, 53-62.

[5] Biddle, G.C. (1980) Accounting Methods and Management Decisions: The Case of Inventory Costing and Inventory Policy. Journal of Accounting Research, 18, 235-280.

[6] Lee, C.J. and Petruzzi, C.R. (1989) Inventory Accounting Switch and Uncertainty. Journal of Accounting Research, 27, 277-296. http://dx.doi.org/10.2307/2491236

[7] Dopuch, N. and Pincus, M. (1988) Evidence on the Choice of Inventory Accounting Methods: LIFO versus FIFO. Journal of Accounting Research, 26, 28-59. http://dx.doi.org/10.2307/2491112

[8] Morse, D. and Richardson, G. (1983) The LIFO/FIFO Decision. Journal of Accounting Research, 21, 106-127. http://dx.doi.org/10.2307/2490939

[9] Lee, C.J. and Hsieh, D.A. (1985) Choice of Inventory Accounting Methods: Comparative Analyses of Alternative Hypotheses. Journal of Accounting Research, 23, 468-485. http://dx.doi.org/10.2307/2490821

[10] Watts, R.L. and Zimmerman, J.L. (1978) Toward a Positive Theory of the Determination of Accounting Standards. The Accounting Review, 53, 112-134.

[11] Cushing, B.E. and LeClere, M.J. (1992) Evidence on the Determinants of Inventory Accounting Policy Choice. The Accounting Review, 67, 355-366.

[12] Christie, A.A. and Zimmerman, J.L. (1994) Efficient and Opportunistic Choices of Accounting Procedures: Corporate Control Contests. The Accounting Review, 69, 539-566.

[13] Niehaus, G.R. (1989) Ownership Structure and Inventory Method Choice. The Accounting Review, 64, 269-284.

[14] Penno, M. and Simon, D.T. (1986) Accounting Choices: Public versus Private Firms. Journal of Business Finance and Accounting, 13, 561-569. http://dx.doi.org/10.1111/j.1468-5957.1986.tb00518.x

[15] Dyl, E.A. (1989) Agency, Corporate Control and Accounting Methods-the LIFO-FIFO Choice. Managerial and Decision Economics, 10, 141-145. http://dx.doi.org/10.1002/mde.4090100209

[16] Plummer, E. and Vigeland, R.L. (2011) Considering Life after LIFO. The CPA Journal, 26-33.

[17] Abdel-Khalik, A.R. (1985) The Effect of LIFO-Switching and Firm Ownership on Executives’ Pay. Journal of Accounting Research, 23, 427-447. http://dx.doi.org/10.2307/2490819

[18] Hunt, H.G. (1985) Potential Determinants of Corporate Inventory Accounting Decisions. Journal of Accounting Research, 23, 448-467.

[19] Dhaliwal, D.S. (1980) The Effect of the Firm's Capital Structure on the Choice of Accounting Methods. The Accounting Review, 55, 78-84.

[20] Cottell, P.G. and Patton, J.M. (1988) The Effect of Inventory Costs on the LIFO Layer Liquidation Decision. Journal of Operations Management, 7, 59-72. http://dx.doi.org/10.1016/0272-6963(81)90004-8

[21] Schiff, A.I. (1983) The Other Side of LIFO. Journal of Accountancy, 155, 120-121. 
[22] Cottell, P.G. (1986) LIFO Layer Liquidation: Some Empirical Evidence. Journal of Accounting, Auditing and Finance, 1, 30-45.

[23] Davis, H.Z., Kahn, N. and Rozen, E. (1984) LIFO Inventory Liquidation: An Empirical Study. Journal of Accounting Research, 22, 480-496. http://dx.doi.org/10.2307/2490660

[24] Granof, M.H. and Short, D. (1984) Why Do Companies Reject LIFO? Journal of Accounting, Auditing, and Finance, 7, 323-333.

[25] Zolfo, F.J. and Cooper, B.N. (1977) Considering the LIFO Election. Management Accounting, 41-43.

[26] Dhaliwal, D.S., Frankeland, M. and Trezevant, R. (1994) The Taxable and Book Income Motivations for a LIFO Layer Liquidation. Journal of Accounting Research, 32, 278-289. http://dx.doi.org/10.2307/2491286

[27] Cohen, M.A. and Pekelman, D. (1979) Optimal Inventory Ordering Policy with Tax Payments under FIFO and LIFO Accounting Systems. Management Science, 25, 729-743. http://dx.doi.org/10.1287/mnsc.25.8.729

[28] Halperin, R. (1979) The Effects of LIFO Inventory Costing on Resource Allocation: A Public Policy Perspective. The Accounting Review, 54, 58-71.

[29] Cohen, M.A. and Halperin, R. (1980) Optimal Inventory Order Policy for a Firm Using the LIFO Inventory Costing Method. Journal of Accounting Research, 18, 375-389. http://dx.doi.org/10.2307/2490584

[30] Bar-Yosef, S. and Sen, P.K. (1992) On Optimal Choice of Inventory Accounting Method. The Accounting Review, 67, 320-336.

[31] Biddle, G.C. and Martin, R.K. (1986) A Stochastic Inventory Model Incorporating Intra-Year Purchases and Accounting Tax Incentives. Management Science, 32, 714-730. http://dx.doi.org/10.1287/mnsc.32.6.714

[32] Blough, C.G., Broad, S.J. and Trueblood, R.M. (1960) Pooling of LIFO in Inventory by Use of Dollar-Value Method. Journal of Accountancy, 2, 33-38.

[33] Tipton, J.S. (2012) IFRS and the Repeal of LIFO. Honors Thesis Project, University of Tennessee, Knoxville.

[34] Reeve, J.M. and Stanga, K. (1987) The LIFO Pooling Decision: Some Empirical Results from Accounting Practice. Accounting Horizons, 25-33.

[35] Cron, W.R. and Hayes, R.B. (1989) The Dollar Value LIFO Pooling Decision: The Conventional Wisdom Is Too General. Accounting Horizon, 3, 57-70.

[36] Kinney, M.R. and Wempe, W.F. (2004) JIT Adoption: The Effects of LIFO Reserve and Financial Reporting and Tax Incentives. Contemporary Accounting Research, 21, 603-638. http://dx.doi.org/10.1506/WYAW-JLGF-XU60-E8CQ

[37] Frankel, M. and Trezevant, R. (1994) The Year-End LIFO Inventory Purchasing Decisions: An Empirical Test. The Accounting Review, 69, 382-398. 
Scientific Research Publishing (SCIRP) is one of the largest Open Access journal publishers. It is currently publishing more than 200 open access, online, peer-reviewed journals covering a wide range of academic disciplines. SCIRP serves the worldwide academic communities and contributes to the progress and application of science with its publication.

Other selected journals from SCIRP are listed as below. Submit your manuscript to us via either submit@scirp.org or Online Submission Portal.
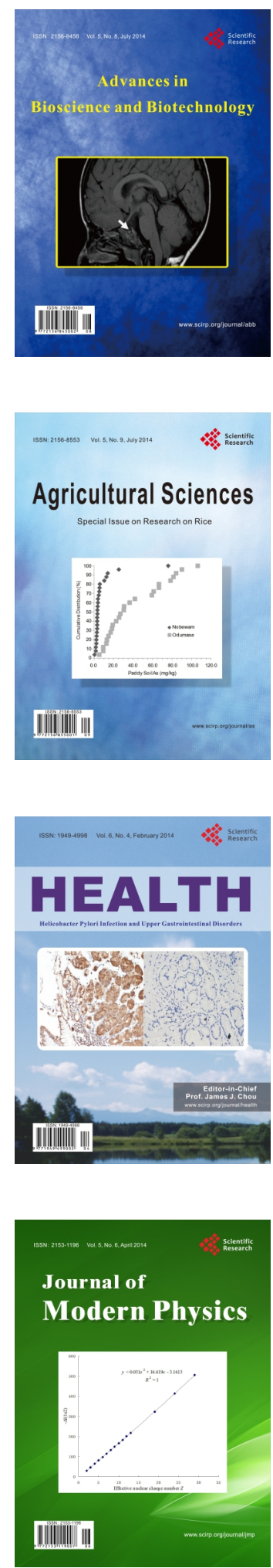
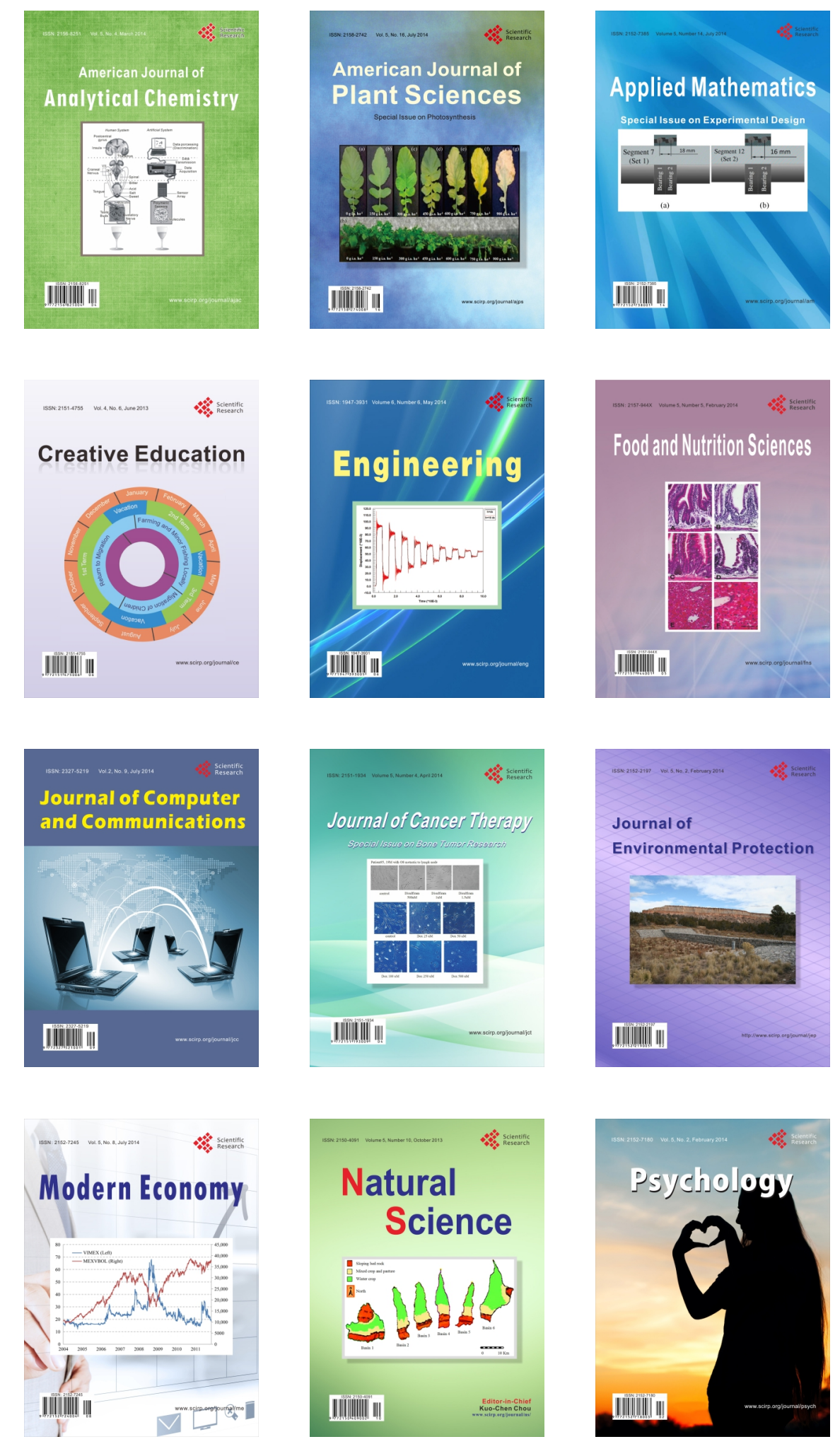